\title{
PROTOTIPE PENILAIAN KINERJA TENAGA AHLI PT. INACON LUHUR PERTIWI DENGAN PENDEKATAN ADAPTIVE NEURO FUZZY INFERENCE SYSTEM
} (ANFIS)

\author{
Handa Gustiawan \\ Program Studi Sistem Informasi Fakultas Ilmu Komputer \\ Universitas MH. Thamrin \\ handagustiawan@gmail.com
}

Abstrak - PT. Inacon Luhur Pertiwi sebagai perusahaan konsultan manajemen dalam melaksanakan pekerjaannya pada proyek PNPM Mandiri Perkotaan berdasarkan kontrak kepada pengguna jasa dengan nomor kontrak HK.02.03/NMC/ IBRD/SATKER-PK/007/2012 tertanggal 10 mei 2012. Dengan melaksanakan metode penelitian kuantitatif, menggunakan data primer dan sekunder sebagai sampel. Data primer diambil dengan melakukan wawancara dan observasi sebagai instrumen observasi penilaian kinerja tenaga ahli. Data sekunder dikumpulkan dengan mengamati data, membaca, mempelajari dan mengutip dari buku literatur, serta sumber-sumber yang berhubungan erat dengan penelitian ini. Data yang didapatkan akan dipergunakan untuk keperluan proses analisis data deskriptif dengan metode Adaptive Neuro-Fuzzy Inference System (ANFIS). Metode ANFIS merupakan metode yang menggunakan jaringan syaraf tiruan untuk mengimplementasikan sistem inferensi fuzzy. Sistem inferensi fuzzy yang digunakan adalah sistem inferensi fuzzy model Tagaki-Sugeno-Kang (TSK) dengan pertimbangan kesederhanaan dan kemudahan komputasi. Hasil dari penelitian ini adalah prototipe penilaian kinerja tenaga ahli yang dapat diimplementasikan pada PT. Inacon Luhur Pertiwi Jakarta.
Kata Kunci : Penilaian Kinerja Tenaga ahli, fuzzy logic, Adaptive Neuro-Fuzzy Inference System (ANFIS).

Abstract - Inacon Luhur pertiwi PT. as a management consulting firm in carrying out its work on the project PNPM Urban with contract number HK.02.03 / NMC / IBRD / SATKER-PK/007/2012 dated 10 May 2012. By carrying out quantitative research methods, using primary and secondary data as samples. Primary data retrieved by conducting an observation as an observation instrument of experts performance assessment. Secondary data was collected by observing the data, reading, studying and quoting from the book of literature, as well as the resources that are closely related to this study. The data obtained will be used for purposes of descriptive data analysis process by using Adaptive Neuro Fuzzy Inference System (ANFIS). ANFIS method is a method that uses neural networks to implement fuzzy inference system. Fuzzy inference system used is the fuzzy inference system models Tagaki-Sugeno-Kang (TSK) with consideration of simplicity and easy computation. The result of this research is the prototipe of expert performance evaluation which can be implemented at Inacon Luhur Pertiwi PT. 
Keywords : experts performance evaluation, fuzzy logic, Adaptive Neuro-Fuzzy Inference

\section{PENDAHULUAN}

PT. Inacon Luhur Pertiwi sebagai perusahaan konsultan manajemen dalam melaksanakan pekerjaannya pada proyek PNPM Mandiri Perkotaan berdasarkan kontrak kepada pengguna jasa dengan nomor kontrak HK.02.03/NMC/IBRD/SATKERPK/007/2012 tertanggal 10 mei 2012 dan didukung oleh Kerangka Acuan Kerja (KAK) melakukan penilaian kinerja terhadap tenaga ahli proyek secara berkala. Pelaksanaan evaluasi kinerja tenaga ahli terhadap pelaksanaan kegiatan proyek harus diposisikan sebagai alat (tools) manajemen untuk pengendalian pelaksanaan suatu rangkaian kegiatan (activities) yang terstruktur sesuai dengan prinsip dan fungsi-fungsi ideal dalam suatu pengelolaan kegiatan/proyek (project management). Secara sederhana, penilaian kinerja didefinisikan oleh Grote [1] sebagai suatu sistem manajemen formal yang disediakan untuk evaluasi kualitas kinerja individu pada sebuah organisasi. Pelaksanaan evaluasi kinerja tenaga ahli dilakukan setiap 4 (empat) bulan, dengan jumlah tenaga ahli lebih dari 50 orang, manajemen berusaha untuk dapat memberikan hasil penilaian kinerja tenaga ahli kepada pengguna jasa dan tenaga ahli tepat waktu dan sesuai dengan KAK.

Sampai saat ini pelaksanaan evaluasi kinerja tenaga ahli hanya dilakukan secara manual dan hanya berupa formalitas serta dilakukan dengan cara yang sangat sederhana sehingga sering terjadi kesalahan dan ketidak akuratan, selain itu juga penilaian tenaga ahli hanya dilakukan untuk pemberian penghargaan dan pemberian hukuman (punishment and reward). Dalam Penilaian kinerja tenaga ahli keluaran yang diharapkan adalah Kurang, Cukup, Baik, yang merupakan pernyataan yang ambigu. Pernyataan ambigu
System (ANFIS).

merupakan karakteristik manusia berkomunikasi secara linguistik dan itu adalah bagian yang terintegrasi dengan proses berfikir. Hal tersebut sangat berbeda dari pemrograman komputer dengan logika boolean yang hanya menyatakan benar dan salah. Logika fuzzy dapat menjembatani perbedaan boolean dengan hal yang ambigu. Logika fuzzy menyediakan suatu cara untuk merubah pernyataan linguistik menjadi suatu numerik [2]. Logika fuzzy adalah logika yang digunakan untuk menjelaskan keambiguan. Logika fuzzy adalah cabang teori dari himpunan fuzzy, himpunan yang menyesuaikan keambiguan [3]. Logika fuzzy adalah suatu cara yang tepat untuk memetakan suatu ruang input kedalam suatu ruang output [4]. Menurut Marimin [5]. fuzzy merupakan perangkat yang tepat untuk mengekspresikan ke-ambiguitas-an.

Logika fuzzy mengevaluasi secara komprehensif, tapi index presisi dan metode evaluasi tidak tercapai dan sulit untuk menentukan bobot evaluasi, untuk itu diperlukan model evaluasi secara rasional, ilmiah dan matematis. Maka dalam penelitian ini dilakukan kolaborasi antara fuzzy dengan neural network. Dan hasilnya adalah dengan penggabungan kedua approach tersebut dihasilkan hasil yang lebih akurat [6]:

Metode ANFIS merupakan metode yang menggunakan jaringan syaraf tiruan untuk mengimplementasikan sistem inferensi fuzzy. Keunggulan sistem inferensi fuzzy adalah dapat menerjemahkan pengetahuan dalam bentuk aturan-aturan, namun biasanya dibutuhkan waktu yang lama untuk menetapkan fungsi keanggotaannya. Oleh sebab itu dibutuhkan teknik pembelajaran dari jaringan saraf tiruan sehingga dapat mengurangi waktu pencarian. Sistem inferensi fuzzy yang digunakan adalah sistem inferensi 
fuzzy model Tagaki-Sugeno-Kang (TSK) dengan pertimbangan kesederhanaan dan kemudahan komputasi. Sistem fuzzy ini digabungkan dengan algoritma pembelajaran neural network.

\section{LANDASAN TEORI}

\subsection{Logika Fuzzy}

Sebelum munculnya teori logika fuzzy (fuzzy logic) dikenal sebuah logika tegas ( crisp logic ) yang memiliki nilai benar dan salah secara tegas. Sebaliknya Logika fuzzy adalah suatu logika yang memiliki nilai kekaburan atau kesamaran ( fuzzy ness ) antara benar atau salah dalam teori logika fuzzy suati nilai bias bernilai benar dan salah secara bersamaan. Namun berapa besar kebenaran dan kesalahan suatu nilai tergantung pada bobot keanggotaan yang dimilikinya. Orang yang belum mengenal logika fuzzy pasti akan mengira bahwa logika fuzzy adalah suatu yang amat rumit dan tidak menyenangkan. Namun, sekali orang mengenalnya,ia pasti akan sangat tertarik dan akan menjadi pendatang baru untuk ikut serta mempelajari logika fuzzy. Logika fuzzy modern dan metodis baru ditemukan beberapa tahun yang lalu, padahal sebenarnya konsep tentang logika fuzzy itu sendiri sudah ada pada diri kita sejak lama [7].

Menurut Sri Kusuma Dewi dan Hari Purnomo,pengertian logika fuzzy adalah suatu cara yang tepat untuk memetakan suatu ruang input ke dalam suatu ruang output,sebagai contoh:

1. Manager perundangan mengatakan pada manager produksi seberapa banyak persediaan barang pada akhir minggu ini, kemudian manager produksi akan menetapkan jumlah barang yang harus diproduksi esok hari.

2. Pelayanan restoran memberikan pelayanan terhadap tamu, kemudian tamu akan memberikan tip yang sesuai atas baik tidaknya pelayanan ang diberikan.

3. Anda mengatakan pada saya seberapa SEJUK ruangan yang anda inginkan, saya akan mengatur putaran kipas yang ada pada ruangan ini.

4. Penumpang taksi berkata pada supir taksi seberapa cepat laju kendaraan yang diinginkan, sopir taksi akan mengatur pinjakan gas taksinya ${ }^{(\mathrm{Sri}, 2002) .}$

\subsection{ANFIS}

Adaptive Neuro-Fuzzy Inference System (ANFIS) merupakan jaringan adaptif yang berbasis pada sistem pada sistem kesimpulan fuzzy (fuzzy infrence system). Dengan penggunaan suatu prosedur hybrid learning. ANFIS dapat membangun suatu mapping input-output yang keduanya berdasarkan pada pengetahuan manusia (pada bentuk aturan fuzzy IF-THEN) dengan fungsi keanggotaan yang tepat.

Sistem kesimpulan fuzzy yang memanfaatkan aturan fuzzy IF-THEN dapat memodelkan aspek pengetahuan manusia yang kualitatif dan memberi reasoning proces tanpa memanfaatkan analisa kuantitatif yang tepat. Ada beberapa aspek dasar dalam pendekatan ini yang membutuhkan pemahaman lebih baik, secara rinci :

1. Tidak ada metoda baku untuk mentransform pengetahuan atau pengalaman manusia kedalam aturan dasar (rule base) dan database tentang fuzzy inference system.

2. Ada suatu kesimpulan bagi metoda efektif untuk mengatur (tuning) fungsi keanggotan (membership function/MF) untuk memperkecil ukuran kesalahan keluaran atau memaksimalkan indeks pencapain.

ANFIS dapat bertindak sebagai suatu dasar membangun satu kumpulan aturan fuzzy IF-THEN dengan fungsi keanggotaan yang tepat, yang berfungsi untuk menghasilkan 
pasangan input-output. Model fuzzy dapat digunakan sebagai pengganti dari percepton dengan banyak lapisan. Dalam hal ini, sistem dapat dibagi menjadi 2 grup, yaitu satu grup berupa jaringan syaraf dengan bobot-bobot fuzzy dan aktifasi fuzzy, dan grup lainnya berupa jaringan syaraf dengan input yang difuzzykan pada lapisan pertama dan kedua, namun bobot-bobot pada jaringan syaraf tersebut tidak difuzzykan. Neuro fuzzy termasuk kelompok yang kedua [8].

ANFIS (adaptive Neuro Fuzzy Inference System atau Adaptive Network-based Fuzzy Inference System) adalah suatu metode yang mana dalam melakukakan penyetelan aturan digunakan algoritma pembelajaran terhadap sekumpulan data. Pada ANFIS juga memungkinkan aturan-aturan untuk beradaptasi [9]. Secara garis besar, arsitektur jaringan ANFIS.

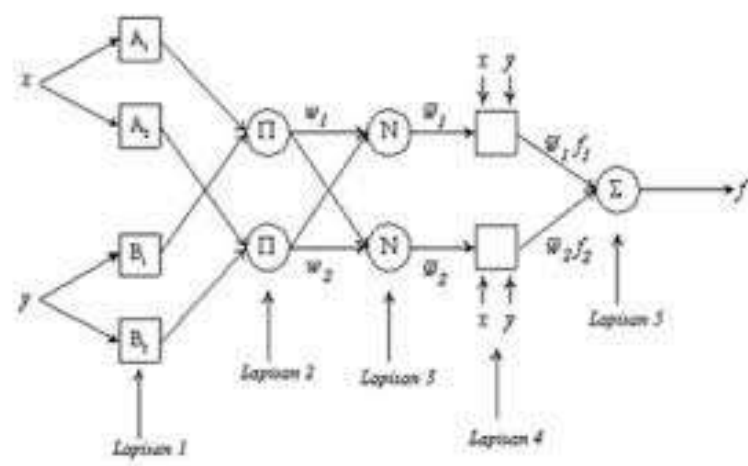

\subsection{Artifical Neural Network}

Jaringan Syaraf Tiruan (Artifical Neural Network) adalah sistem pemroses informasi dengan karakteristik dan performa yang mendekati syaraf biologis. Jaringan syaraf tiruan adalah generalisasi dari permodelan syaraf biologi dengan asumsi asumsi antara lain [10].

1. Pemrosesan informasi terletak pada sejumlah komponen yang dinamakan neuron. Sinyal merambat antara satu neuron ke neuro-neuron yang lainnya melalui jalur penghubung.
2. Tiap jalur penghubung memiliki bobot dan mengalihkan besar nilai sinyal yang masuk (jenis neuron tertentu)

3. Tiap neuron menerapkan fungsi aktivasi (biasanya non linear) yang menjumlahkan semua masukan umtuk menentukan sinyal keluarannya. Tiap jaringan ditentukan oleh arsitektur pola jaringan, bobot, pada koneksi dan fungsi aktifasi.

Selain memproses, jaringan syaraf tiruan juga memiliki kemapuan menyimpan informasi. Jaringan syaraf adalah pemroses sederhana yang berjumlah banyak dan bekerja secara paralel dan terdistribusi, yang memiliki kemampuan menyimpan pengetahuan dan memberikan saat dibutuhkan terdiri dari pengetahuan yang dimiliki sebagai hasil proses pembelajarn dan koneksi antar neuron yang berfungsi menyimpan pengetahuan itu. Sedangkan jaringan syaraf tiruan bermaksud membuat sistem yang menyerupai syaraf tiruan biologis.

\subsection{Metode Least Significant Bit (LSB)}

Penalaran dengan metode Sugeno hampir sama dengan penalaran Mamdani, hanya saja output (konsekuen) sistem tidak berupa himpunan fuzzy, melainkan berupa konstanta atau persamaan linear. Metode ini diperkenalkan oleh Takagi-Sugeno Kang pada tahun 1985, sehingga ini sering juga dinamakan dengan TSK. Metode TSK terdiri dari 2 jenis, yaitu :

1. Model Fuzzy Sugeno Orde-Nol Secara umum bentuk model fuzzy Sugeno Orde Nol adalah: IF (x1 is A1) o (x2 is A2) o ( $\mathrm{x} 3$ is $\mathrm{A} 3$ ) o... o ( $\mathrm{xN}$ is $\mathrm{AN})$ THEN $\mathrm{z}=\mathrm{k}$ dengan $\mathrm{Ai}$ adalah himpunan fuzzy ke-I sebagai antesenden, dan $\mathrm{k}$ adalah suatu konstanta (tegas) sebagai konsekuen.

2. Model Fuzzy Sugeno Orde-Satu Secara umum bentuk model fuzzy Sugeno OrdeSatuadalah: IF ( $\mathrm{x} 1$ is $\mathrm{A} 1)$ o... o ( $\mathrm{xN}$ is $\mathrm{AN})$ THEN $\mathrm{z}=\mathrm{p} 1 * \mathrm{x} 1+\ldots+\mathrm{pN} * \mathrm{xN}+\mathrm{q}$ dengan $\mathrm{Ai}$ adalah himpunan fuzzy ke-i 
sebagai antesenden, dan pi adalah suatu konstanta (tegas) ke-i dan q juga merupakan konstanta dalam konsekuen. Apabila komposisi aturan mengguanakan metode SUGENO, maka deffuzifikasi dilakukan dengan cara mencari nilai rataratanya.

Sistem fuzzy sugeno memperbaiki kelemahan yang dimiliki oleh sistem fuzzy murni untuk menambah suatu perhitungan matematika sederhana sebagai bagian THEN. Pada perubahan ini, sistem fuzzy memiliki suatu nilai rata-rata tertimbang (Weighted Average Values) didalam bagian aturan fuzzy IF_THEN.

\subsection{Penilaian Tenaga Ahli}

Pelaksanaan evaluasi terhadap kinerja penyelenggaraan kegiatan PNPM Mandiri Perkotaan oleh NMC, perlu difokuskan pada kebutuhan dan kepentingan untuk mengakomodasi seluruh substansi yang terkandung dalam landasan dan basis seperti tersebut di atas. Dalam konteks ini, evaluasi kinerja Tenaga Ahli dan Specialist NMC terhadap pelaksanaan kegiatan PNPM Mandiri Perkotaan harus diposisikan sebagai alat (tools) manajemen untuk pengendalian pelaksanaan suatu rangkaian kegiatan (activities) yang terstruktur sesuai dengan prinsip dan fungsi-fungsi ideal dalam suatu pengelolaan kegiatan/proyek (project management).

Kinerja (performance) diterminologikan sebagai unjuk atau tampilan kerja dalam suatu pelaksanaan kegiatan untuk perioda waktu tertentu. Hasil pencapaian kinerja umumnya dikaitkan dan diukur terhadap tujuan dan sasaran yang telah ditetapkan oleh organisasi/proyek. Dalam manajemen, konsep kinerja diterjemahkan sebagai upaya organisasi untuk melakukan penilaian terhadap SDM yang ada, baik dari sisi kemampuan bekerja, capaian hasil kerja maupun perilaku kerja. Sedangkan penilaian terhadap kinerja organisasi (organizational performance) juga dilakukan melalui penilaian terhadap para pengelola/pengendali kegiatan sebagai manajer atau dikenal dengan managerial performance appraisal as managers.

Dalam mengukur kinerja, sistem yang digunakan untuk melakukan penilaian terhadap tujuan-tujuan terpilih yang ditetapkan; akan mempunyai peran dan nilai yang sangat signifikan. Faktor-faktor konsistensi, keterpaduan dan pemahaman terhadap rancangan rencana untuk meraih sasaran-sasaran khusus, kemungkinannya merupakan kriteria terbaik dari kinerja manajerial terkait pada kemampuan untuk menetapkan tujuan-tujuan secara strategis, merencanakan program yang dapat memenuhi tujuan-tujuan tersebut serta berhasil untuk mencapainya. Keseluruhan faktor dan aspek yang telah dioperasionalkan dalam satu variasi sistem ini, sering mendapatkan tuntutan bahwa kriteria-kriteria tersebut tidak mencukupi sebagai basis penilaian. Selain itu elemen-elemen yang tidak menguntungkan atau merupakan faktor-faktor lain di luar kendali para manajer/atasan, sering diperhitungkan dalam melakukan penilaian. Sehingga dapat dikatakan bahwa penilaian yang hanya ditujukan terhadap sasaransasaran yang telah ditetapkan tidak cukup untuk digunakan sebagai dasar penilaian kinerja SDM.

\section{DESAIN PENELITIAN}

3.1. Metode penelitian

Penelitian ini menggunakan metode analisis kuantitatif yaitu penelitian yang menggunakan angka-angka yang dijumlahkan sebagai data yang kemudian dianalisis. Metode ini dimaksudkan untuk menjelaskan fenomena dengan menggunakan data-data numerik, kemudian dianalisis yang umumnya menggunakan statistik [11], untuk 
mendapatkan gambaran yang lebih mendalam dan lengkap dari objek yang diteliti dengan melakukan pengamatan langsung dilapangan

\subsection{Sampling / Metode Pemilihan Sampel}

Dalam metode pemilihan sampel data yang diambil adalah data sekunder yaitu data yang telah dikumpulkan oleh penulis pada kantor proyek PNPM Mandiri perkotaan. Sampel diambil terhadap 5 tenaga ahli dari populasi sebesar 53 tenaga ahli.

Pengamatan dan Pemantauan dilakukan oleh petugas penilai dari PT. Inacon Luhur Pertiwi. Waktu Pengamatan dilakukan dari tanggal 01 Oktober 2015 - 30 November 2015

\subsection{Metode Pengumpulan Data}

Pengumpulan data merupakan bagian paling penting dalam sebuah penelitian. Ketersediaan data akan sangat menentukan dalam proses pengolahan dan analisa selanjutnya. Karenanya, dalam pengumpulan data harus dilakukan teknik yang menjamin bahwa data diperoleh itu benar, akurat dan bisa dipertanggungjawabkan sehingga hasil pengolahan dan analisa data tidak bias. Pengumpulan data tenaga ahli dilakukan mulai tanggal 1 Oktober 2015 sampai dengan tanggal 30 November 2015. Untuk mengumpulkan data dan informasi tersebut, dilakukan metode pengumpulan data sebagai berikut:

1. Pengumpulan data primer

Metode ini digunakan untuk mendapatkan data primer, yaitu dengan melakukan wawancara sesuai dengan kebutuhan dan kondisi yang ada.

2. Pengumpulan data sekunder

Data sekunder dikumpulkan dengan mengamati data, membaca, mempelajari dan mengutip dari buku literatur, serta sumber-sumber yang berhubungan erat dengan penelitian ini.

\subsection{Teknik Analisis dan Pengujian Data}

1. Analisis Deskriptif

Analisis deskriptif adalah cara analisis dengan mendeskripsikan atau menggambarkan data yang telah terkumpul sebagaimana adanya tanpa membuat kesimpulan yang berlaku untuk umum atau generalisasi. Tujuan analisis ini dimaksudkan untuk mendapatkan data penilaian kinerja tenaga ahli terhadap 5 tenaga ahli selama 2 bulan yaitu dimulai tanggal 01 Oktober 2015 sampai dengan 30 November 2015 yang meliputi : kompetensi. Kompetensi, Sikap dan Perilaku, Etika Kerja serta Kedisplinan.

2. Analisis Inferential

Teknik penelitian yang digunakan untuk menganalisa data dan menguji hipotesis pada penelitian ini menggunakan Hybrid Algorithm dan Backpropagation Algorithm. Tujuan utama analisis inferential dengan menggunakan Hybrid Algorithm dan Backpropagation Algorithm adalah untuk memperoleh parameter yang paling optimal dengan masalah yang sedang dikaji dalam penelitian ini.

\subsection{Langkah-langkah Penelitian}

Langkah langkah penelitian yang diambil penulis dalam rangka melaksanakan pola pikir pemecahan masalah, yaitu :

1. Penentuan Masalah

Penulis mengambil masalah proses Penilaian Kinerja Tenaga ahli dengan memaparkan kompetensi yang ada, serta indikator yang ada di dalamnya atau dengan kata lain Menentukan Parameter. Parameter yang digunakan ada 4 (empat) input yaitu, Kompetensi, Sikap dan Perilaku, Etika Kerja, dan Kedisiplinan. Output yang dihasilkan yaitu Kinerja tenaga ahli

2. Pendekatan Komputasi untuk Pemecahan Masalah 
Pendekatan komputasi yang diambil untuk penyelesaian masalah terhadap penilaian kinerja tenaga ahli adalah memakai pendekatan adaptive neuro-fuzzy inference system (ANFIS) dengan melakukan Fuzzy-fikasi parameter (Membership-function) langkah-langkah berikut:

- Membership-function Kompetensi

- Membership-function Sikap dan Perilaku

- Membership-function Etika Kerja

- Membership-function Kedisplinan

Contoh pembuatan membership function dapat dilihat sebagai berikut:

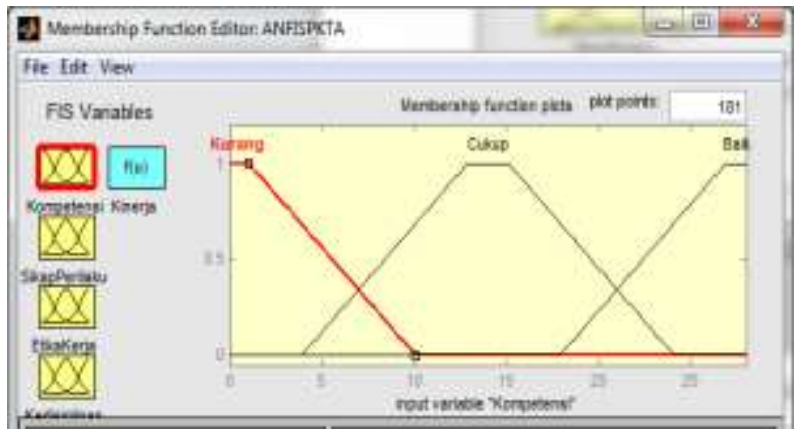

3. Pengujian dan Implementasi

Setelah proses pembentukan FIS, maka akan dibuat jaringan syaraf tiruan yang terdiri dari 3 masukan, 1 keluaran, 81 rule

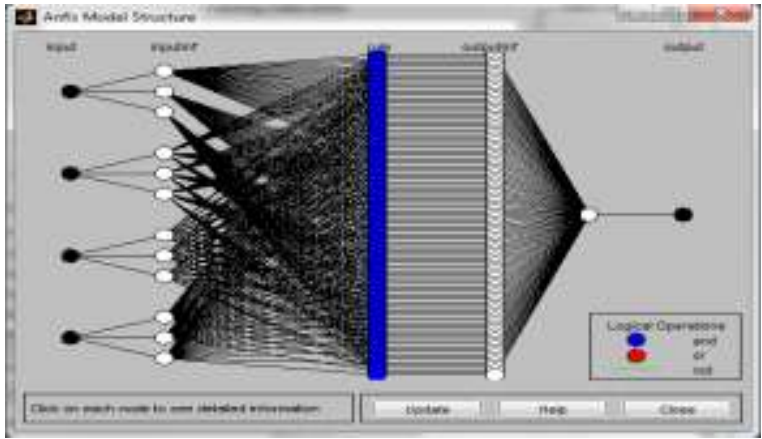

yang didapat dari jumlah membership function (MF) adalah (3 333 ).

Di dalam pengujian dan analisis penulis mencoba menghitung secara manual dan otomatis menggunakan Matlab. Penulis akan menganalisa menggunakan algoritma Error Backpropagation (EBP) untuk memperoleh parameter yang paling optimal dengan masalah sedang diteliti.

4. Pembuatan Laporan

penulis akan melanjutkan pembuatan laporan untuk tesis untuk analisa data dan penjelasan tentang sistem penilaian kinerja tenaga ahli.

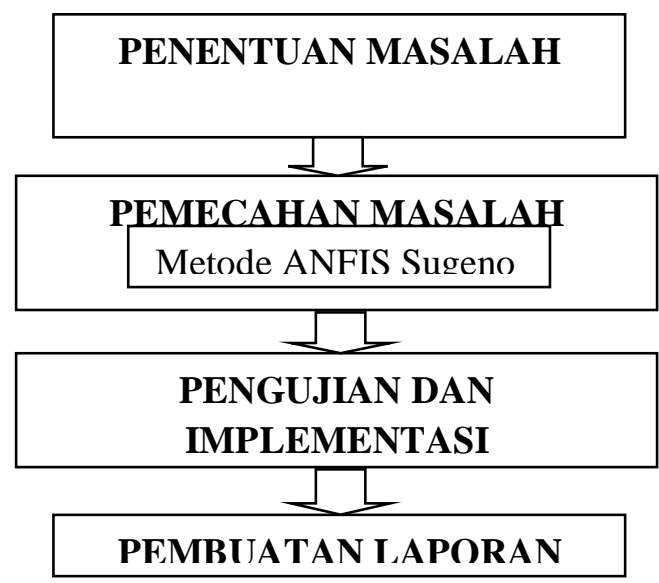

\subsection{Pengelompokan dan Analisis Data}

\subsubsection{Pengelompokan Data}

FIS (Fuzzy Inference System) Penilaian Kinerja Tenaga Ahli mempunyai 4 (empat) variabel input dan 1 (satu) variabel output yaitu:

\begin{tabular}{|c|c|}
\hline Variabel Input & Variabel Output \\
\hline 1. Kompetensi & - Baik \\
\hline 2. Sikap dan Perilaku & - Cukup \\
\hline 3. Etika Kerja & \multirow[t]{2}{*}{ - Kurang } \\
\hline 4. Kedisiplinan & \\
\hline
\end{tabular}


Untuk membangun FIS memerlukan semesta pembicaraan. Semesta pembicaraan yang dibentuk terlihat pada tabel dibawah ini.

\subsubsection{Analisis Data}

Data penelitian PKTA ini berjumlah 53 data yang dibagi dalam kelompok, yaitu:

a. 20 data pertama digunakan sebagai Training-Data ( Data Latihan )

b. 20 data kedua digunakan sebagai TestingData ( Data Pengujian Validitas )

c. 13 data ketiga digunakan sebagai CheckData ( Data Checking )

d. 53 data keseluruhan digunakan sebagai ujicoba GUI

\subsubsection{Simulasi Adaptive Neuro Fuzzy Inference System ( ANFIS )}

Tahapan dalam proses simulasi ANFIS Penilaian Kinerja Tenaga ahli terdiri dari :

a. Tahap Load Data ( Tahap Memasukan Data )

b. Tahap Generate FIS ( Taham Membangkitkan FIS )

c. Tahap Train FIS ( Tahap Pembelajaran FIS )

\subsubsection{Tahap Load Data}

\section{Tahap Load Data}

Tahap ini merupakan tahap untuk meload data baik data trining, data testing dan data checking. Adapun untuk memasukan ketiga jenis data tersebut dapat dilakukan dengan cara melakukan load data.

ANFIS Editor GUI harus diaktifkan terlebih dahulu dengan mengetikkan

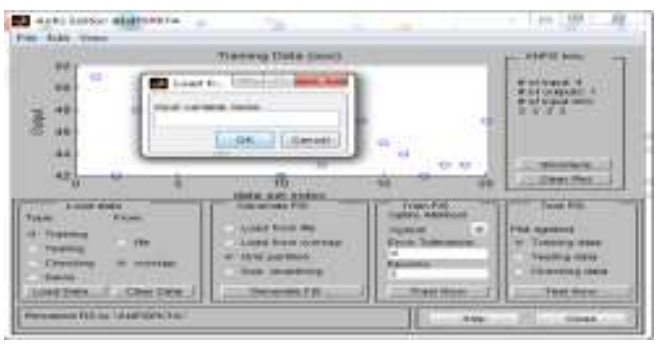

>>anfisedit pada command windows yang ada di matlab yang selengkapnya dapat dilihat pada gambar

Gambar diatas menunjukan proses load

\begin{tabular}{|c|c|l|}
\hline Fungsi & Variabel & $\begin{array}{c}\text { Semesta } \\
\text { pembicaraan }\end{array}$ \\
\hline \multirow{3}{*}{ Input } & Kompetensi & {$[0-28]$} \\
\cline { 2 - 3 } & $\begin{array}{c}\text { Sikap dan } \\
\text { Perilaku }\end{array}$ & {$[0-12]$} \\
\cline { 2 - 3 } & Etika Kerja & {$[0-8]$} \\
\cline { 2 - 3 } & Kedisiplinan & {$[0-8]$} \\
\hline Output & Out & {$[0-56]$} \\
\hline
\end{tabular}

data latihan untuk keperluan proses penilaian kinerja tenaga ahli dengan nama workspace DataTrain.mat (Data Latihan )yang telah

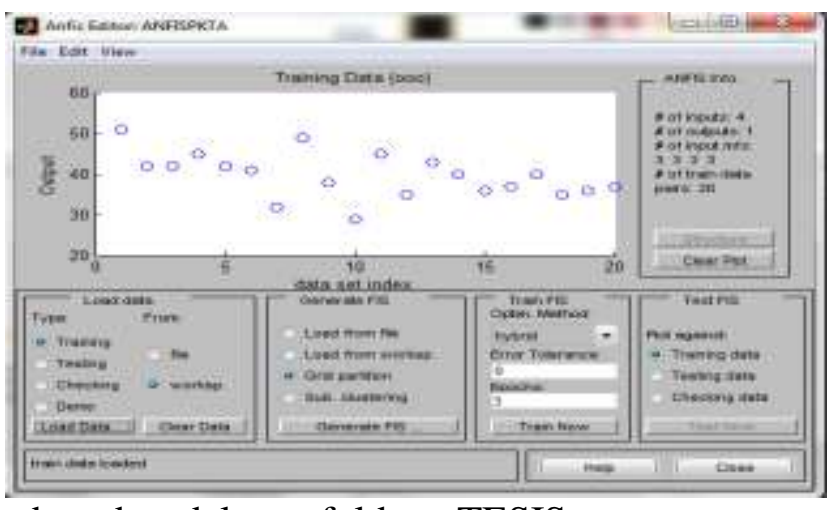

berada dalam folder TESIS yang nama iconnya disimbolkan dalam sebuah tumpukan buku atau arsip kecil.

\section{a. Load Data Latihan ( Training-Data)}

DataTrain.mat atau Training Data ( Data Latihan ) pada ANFISPGK.fis yang digunakan 20 data pertama dengan 4 variabel input yaitu kompetensi, sikapperilaku, etikakerja, kedisiplinan dan 1 variabel output yaitu KinerjaTA ( Nilai Penilaian Kinerja Tenaga ahli ) dengan nomor input MFs 3333 yaitu terdiri dari domain kompetensi 3 domain sikapperilaku 3 domain etikakerja 3 domain kedisiplinan 3 dan hasil berupa KURANG, CUKUP, BAIK dari masing-masing kompetensi tersebut. Data Training-PKTA 
dapat dilihat pada dalam memory yang disimbolkan oleh neuron bola-bola

b. Load Data Pengujian ( Testing dan Validasi )

DataTest.mat atau Testing Data ( Data Pengujian ) pada pada ANFISPGK.fis yang digunakan 20 data pertama dengan 4 variabel input yaitu kompetensi, sikapperilaku, etikakerja, kedisiplinan dan 1 variabel output yaitu KinerjaTA ( Nilai Penilaian Kinerja Tenaga ahli ) dengan nomor input MFs 3333 yaitu terdiri dari domain kompetensi 3 domain sikapperilaku 3 domain etikakerja 3 domain kedisiplinan 3 dan hasil berupa KURANG, CUKUP, BAIK dari masing-masing kompetensi tersebut. Data Test PKTA dapat dilihat pada dalam memory yang disimbolkan oleh neuron bintang-bintang kecil

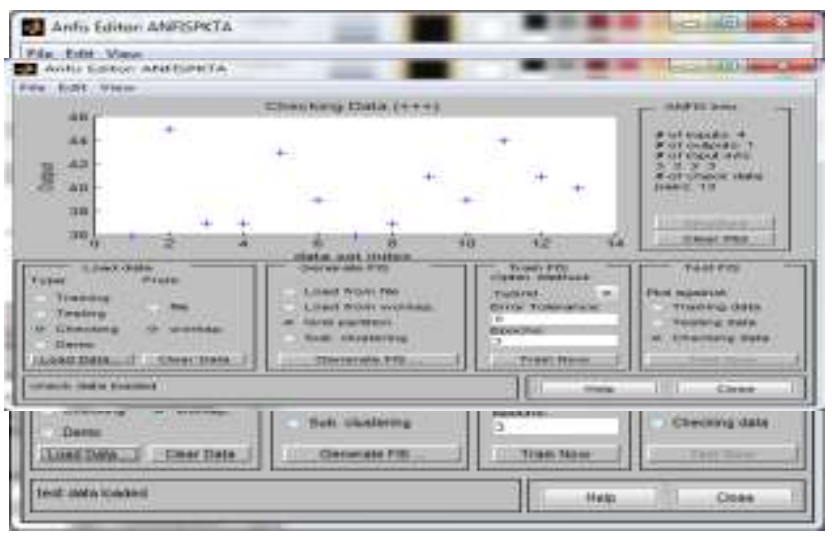

c. Load Data Pengecekan ( Checking)

DataCheck.mat atau Checking Data ( Data Pengecekan ) pada ANFISPGK.fis yang digunakan 20 data pertama dengan 4 variabel input yaitu kompetensi, sikap perilaku, etikakerja, kedisiplinan dan 1 variabel output yaitu KinerjaTA ( Nilai Penilaian Kinerja Tenaga ahli ) dengan nomor input MFs 3333 yaitu terdiri dari domain kompetensi 3 domain sikapperilaku 3 domain etikakerja 3 domain kedisiplinan 3 dan hasil berupa KURANG, CUKUP, BAIK dari masing-masing kompetensi tersebut. Data Check-PKTA dapat dilihat pada dalam memory yang disimbolkan oleh neuron plus-plus kecil

\subsubsection{Tahap Generate FIS ( Fuzzy Inference System )}

Sebelum dapat melakukan proses pembelajaran, maka harus dibandingkan terlebih dahulu struktur dari model FIS. Untuk keperluan ini digunakan Grid-Partition untuk membandingkan Single Output Sugeno FIS dengan mengklik menu Edit-Membership functions ( $\mathrm{Crtl}+2$ )setelah melakukan load data pada gambar IV-6 dan load data yang lainnya.

a. Parameter Input

Meliputi banyaknya INPUT-MF ( Membership Functions ) dalam kasus ini dinyatakan dengan $\left[\begin{array}{lllll}3 & 3 & 3 & 3\end{array}\right]$, sedangkan tipe MF yang digunakan dalam kasus ini ada 6 tipe: trimf, trapmf, gbellmf, gaussmf, gauss $2 \mathrm{mf}$, Pimf

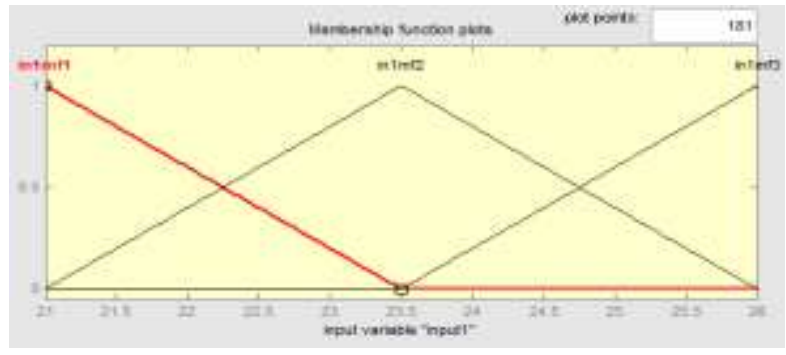

b. Parameter Output

Ada 2 parameter output, yaitu tipe constant dan linier, dalam penelitian ini akan digunakan parameter output jenis constant.

\subsubsection{Tahap Training dan Testing Generate FIS}

Model akan dibangun dengan 2 Algoritms, yaitu:

a. Algoritma hybrid ( Backpropagation + Least Square Estimation )

b. Algoritma Backpropagation 


\begin{tabular}{|r|l|r|r|}
\hline No & $\begin{array}{l}\text { Kungsi } \\
\text { Keanggotaan }\end{array}$ & \multicolumn{2}{|c|}{$\begin{array}{c}\text { RMSE (Root Mean Square } \\
\text { Error) }\end{array}$} \\
\hline & & $\begin{array}{l}\text { Hybrid } \\
\text { Algorithm }\end{array}$ & $\begin{array}{l}\text { Backpropagation } \\
\text { Algorithm }\end{array}$ \\
\hline 1 & trimf & 20.7745 & 37.8919 \\
\hline 2 & tramf & 22.9857 & 38.0983 \\
\hline 3 & gbellmf & 22.131 & 37.9248 \\
\hline 4 & gaussmf & 19.9988 & 37.9237 \\
\hline 5 & gauss2mf & 24.1451 & 38.7264 \\
\hline 6 & pimf & 23.4368 & 38.078 \\
\hline
\end{tabular}

\subsection{Temuan-temuan dan Interpretasi Model}

\subsubsection{Temuan-Temuan}

Berdasarkan simulasi anfis yang telah dilakukan, maka didapatkan hasil perbandingan simulasi dengan kategori pada algoritma yang digunakan, yaitu hybrid algorithm dan backpropagation algorithm, selain itu juga berdasarkan kategori parameter dari tipe MF (membership function) pada setiap tahap simulasi yang digunakan.

\begin{tabular}{|c|c|c|c|}
\hline \multirow[t]{2}{*}{ No } & \multirow[t]{2}{*}{$\begin{array}{l}\text { Fungsi } \\
\text { Keanggotaan }\end{array}$} & \multicolumn{2}{|c|}{ RMSE (Root Mean Square Error) } \\
\hline & & $\begin{array}{l}\text { Hybrid } \\
\text { Algorithm }\end{array}$ & $\begin{array}{l}\text { Backpropagation } \\
\text { Algorithm }\end{array}$ \\
\hline 1 & trimf & 0.000097471 & 42.9538 \\
\hline 2 & $\operatorname{tramf}$ & 0.15812 & 42.7825 \\
\hline 3 & gbellmf & $\underline{0.000063629}$ & 42.5848 \\
\hline 4 & gaussmf & 0.000136 & 42.5378 \\
\hline 5 & gauss $2 m f$ & 0.000146 & 42.7701 \\
\hline 6 & $\operatorname{pimf}$ & 0.15811 & 42.7679 \\
\hline
\end{tabular}

Tabel diatas menunjukan nilai RMSE untuk kedua algorithm, hybrid algorithm dan backpropagation algorithm pada proses pembelajaran penilaian kinerja Tenaga Ahli.

Table diatas menunjukan nilai RMSE untuk kedua algoritma, hybrid algorithm dan backpropagation algorithm pada proses validasi (Testing) dari proses pembelajaran penilaian Kinerja Tenaga Ahli di PNPM Mandiri Perkotaan.

\subsubsection{Interpretasi Model}

a. Model Proses Pembelajaran (Training)

Berdasarkan perbandingan Root Mean square Error (RMSE) proses pembelajaran, algoritma pembelajaran yang paling optimal untuk kasus ini adalah Hybrid Algorithm, tipe Membership Function (MF) : gbellmf, Epoch : 500, parameter input : [ $\left.\begin{array}{llll}3 & 3 & 3 & 3\end{array}\right]$ ], terdiri dari 81 rule yang digambarkan seperti berikut:

Gambar diatas menunjukan proses pembelajaran dengan menggunakan training data, dengan algoritma Hybrid yang menggunakan Membership Function bertipe : gbellmf, epoch proses pembelajaran sebesar 500 epoch. Sehingga menghasilkan error dengan nilai $\mathrm{RMSE}=0,000063629$ pada epoch atau pengulangan pengujian \pm 500 .

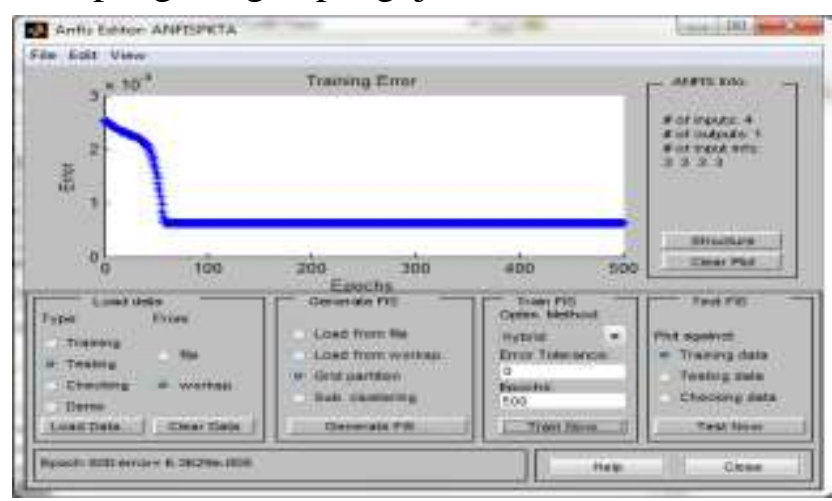

\section{b. Model Proses Validasi (Testing)}

Berdasarkan perbandingan root mean square error (RMSE) proses pembelajaran, algoritma testing validasi yang paing optimal untuk kasus ini adalah Hybrid Algorithm, tipe Membership Function (MF) : gaussmf, Epoch : 500, Parameter Input : [ $\begin{array}{llll}3 & 3 & 3 & 3\end{array}$ ], terdiri dari 81 rule yang digambarkan seperti berikut : 


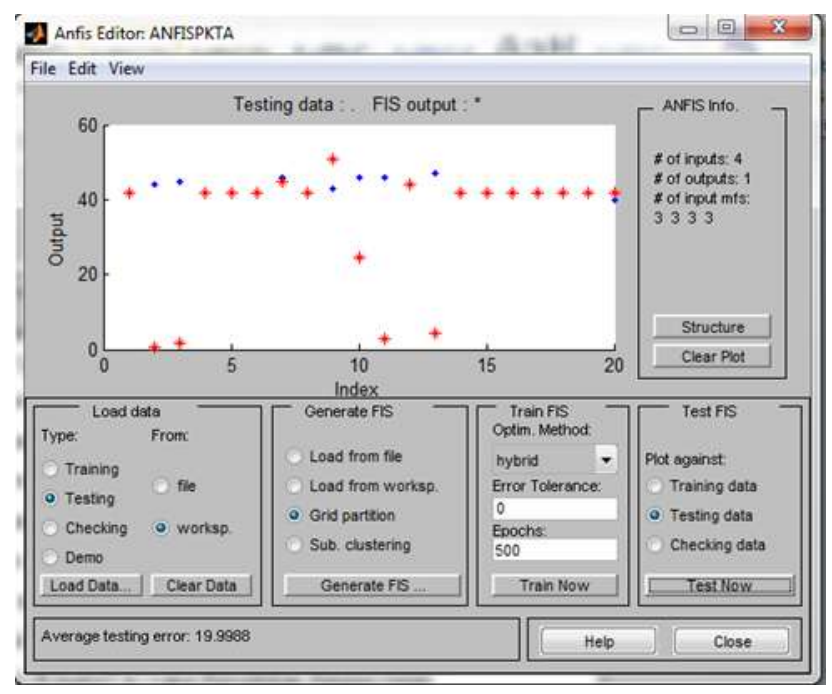

Gambar diatas menunjukan proses validasi dengan menggunakan testing data, dengan algoritma Hybrid yang menggunakan Membership Fuction bertipe : gaussmf, epoch proses validasi sebesar 500 epoch. Sehingga menghasilkan error dengan nilai RMSE = 19.9988 .

\section{c. Surface Viewer}

Proses ini berguna untuk melihat gambar pemetaan antara variabel-variabel input dan varibel-variabel output. Viewer ini dapat dipanggil dengan cara memilih menu viewview surface atau menekan tombol ctrl+6 maka akan muncul surface viewer

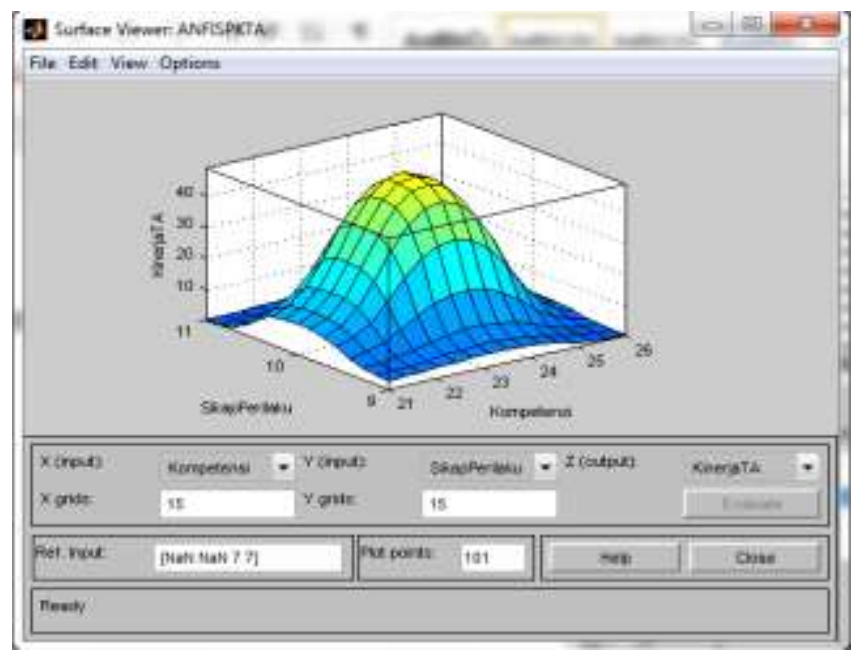

\subsection{Rancangan GUI Penilaian Kinerja Tenaga Ahli \\ Rancangan tampilan GUI sebagai berikut :}

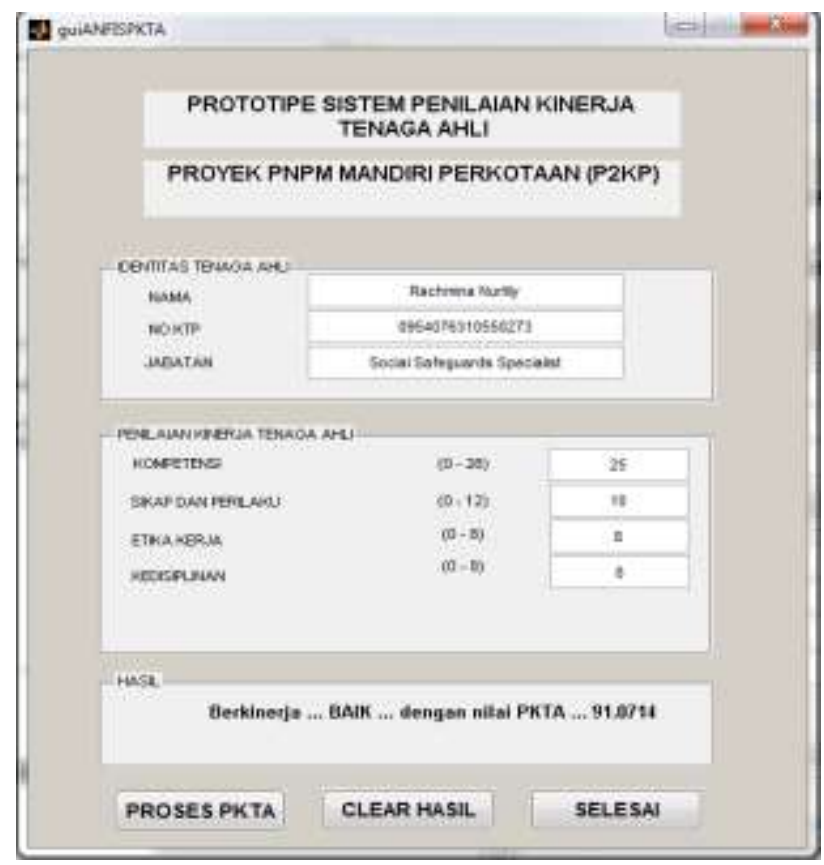

Gambar diatas menunjukan GUI sistem penilaian Kinerja Tenaga Ahli (PKTA) dimana sistem tersebut akan menampilkan output berupa keterangan apakah Tenaga Ahli tersebut memiliki himpunan kinerja yang KURANG, CUKUP atau BAIK untuk mendapatkan tunjangan tambahan atau tidak ditentukan oleh 4 kriteria inputan yaitu Kompetensi dengan rentang nilai 0 - 28, Sikap Perilaku dengan rentang nilai 0-12, Etika Kerja dengan rentang nilai 0-8 dan Kedisiplinan dengan rentang nilai 0-8 yang mana rule yang dipakai adalah rule yang didapat pada anfis. GUI program penilaian kinerja Tenaga Ahli (guiANFISPKTA.fig) ini dibangun dengan menggunakan tool MATLAB dengan fungsi $A N D$ dengan membandingkan data yang terdapat pada penilaian kinerja yang ada secara keseluruhan telah dibentuk FIS dengan nama file ANFISPKTA.fis. 


\subsection{Pengujian Prototipe}

Untuk memastikan bahwa perangkat lunak yang dibuat memiliki suatu standar maksimal kualitas, maka metode yang akan dipakai untuk pengukuran perangkat lunak secara kuantitatif pada penelitian ini adalah dengan metode SQA (Software Quality Assurance).

\begin{tabular}{|c|c|c|c|}
\hline No & Metrik & Deskripsi & Bobot \\
\hline 1 & Auditability & Memenuhi standar atau tidak & 0,125 \\
\hline 2 & Accuracy & Keakuratan komputasi & 0,125 \\
\hline 3 & Completeness & Kelengkapan & 0,125 \\
\hline 4 & $\begin{array}{l}\text { Error } \\
\text { Tolerance }\end{array}$ & Toleransi terhadap kesalahan & 0,125 \\
\hline 5 & $\begin{array}{l}\text { Execution } \\
\text { Efficiency }\end{array}$ & Kinerja eksekusi & 0,125 \\
\hline 6 & Operability & $\begin{array}{l}\text { Kemudahan untuk } \\
\text { diopersikan }\end{array}$ & 0,125 \\
\hline 7 & Simplicity & kemudahan untuk dipahami & 0,125 \\
\hline 8 & Training & $\begin{array}{l}\text { Kemudahan pembelajaran } \\
\text { fasilitas }\end{array}$ & 0,125 \\
\hline \multicolumn{3}{|r|}{ Total Bobot } & 1 \\
\hline
\end{tabular}

Tabel ini menggambarkan ada 8 buah kriteria yang dapat digunakan untuk mengukur kualitas sebuah perangkat lunak secara kuantitatif.

\begin{tabular}{|c|c|c|c|c|c|c|c|c|c|}
\hline \multirow{2}{*}{ User } & \multicolumn{7}{|c|}{ Nilai Metrik } & \multirow{2}{*}{ Nilai } \\
\cline { 2 - 10 } & $\mathbf{1}$ & $\mathbf{2}$ & $\mathbf{3}$ & $\mathbf{4}$ & $\mathbf{5}$ & $\mathbf{6}$ & $\mathbf{7}$ & $\mathbf{8}$ & \\
\hline 1 & 80 & 80 & 80 & 80 & 80 & 80 & 80 & 80 & 80,00 \\
\hline 2 & 78 & 80 & 80 & 76 & 82 & 79 & 82 & 78 & 79,38 \\
\hline 3 & 79 & 80 & 81 & 79 & 85 & 81 & 80 & 85 & 81,25 \\
\hline 4 & 80 & 83 & 76 & 82 & 76 & 80 & 79 & 80 & 79,50 \\
\hline 5 & 80 & 79 & 82 & 78 & 80 & 82 & 79 & 82 & 80,25 \\
\hline \multicolumn{8}{|c|}{ rata-rata } \\
\hline
\end{tabular}

\subsection{Implikasi Penelitian}

\subsubsection{Aspek Sistem}

\subsubsection{Hardware}

Saat ini hampir disemua perkantoran sangat membutuhkan komputer untuk mempermudah pekerjaan ataupun sebagai media pembelajaran, khususnya PT. Inacon Luhur Pertiwi yang membawahi banyak proyek termasuk proyek PNPM Mandiri
Perkotaan, wajib hukumnya memiliki komputer dengan perangkat keras terdepan karena untuk menunjang pekerjaan sekaligus menjadi acuan dari setiap proyek-proyek yang dinaunginya. Juga untuk menunjang sistemsistem yang akan diaplikasikan dimasa mendatang membutuhkan pembaharuan hardware untuk bisa dijalankan.

\subsubsection{Software}

Software yang mendukung penelitian ini adalah Matlab didapat hasil yang cukup akurat dan efisien, untuk pengembangan bisa dihubungkan dengan program lain untuk visualisasi yang lebih baik dan cakupan program yang lebih luas.

\subsubsection{Infrastruktur}

Teknologi informasi adalah pasangan yang tidak terpisahkan dari sebuah komputer karena disaat ini kebutuhan teknologi informasi tidak hanya terbatas untuk perusahaan skala besar tetapi juga kebutuhan dari setiap manusia perorangan. Penggunaan sistem penilaian kinerja tenaga ahli yang cepat dan akurat serta fasilitas internet dalam penyebaran informasi akan sangat membantu tenaga ahli dan perusahaan dalam perubahan kearah yang lebih baik.

\subsubsection{Mekanisme}

Untuk penilaian kinerja tenaga ahli diperlukan mekanisme pengelolaan sistem informasi agar tidak ketinggalan dengan teknologi terbaru, baik juga setiap aspek pekerjaan umum, seperti penilaian, promosi dll menggunakan otomisasi sistem selain untuk mempercepat proses pengerjaan.

\subsubsection{Aspek Manajerial \\ 4.5.2.1 Organisasi dan Prosedur}

Dari segi organisasi, pembuatan sistem PKTA di PNPM Mandiri Perkotaan berpengaruh besar karena menimbulkan ide untuk memiliki staf IT khusus proyek PNPM 
Mandiri Perkotaan yang bertugas mengotomisasi sistem dari setiap pekerjaan yang ada karena selama ini staf IT hanya dimiliki oleh PT. Inacon Luhur Pertiwi.

\subsubsection{Sumber Daya Manusia}

Dari segi SDM sistem PKTA ini sangat bermanfaat karena jika tadinya untuk menghitung bobot penilaian kinerja tenaga ahli ini mempekerjakan tenaga kontrak, sekarang sudah ada sistem yang menggantikan tugasnya, jadi akan membuat pengawasan proyek lebih efektif.

\subsubsection{Pendidikan dan Latihan}

Sistem PKTA ini dibuat memang untuk menunjang pelaksanaan proyek PNPM Mandiri Perkotaan, karena setiap tenaga ahli akan mendapat evaluasi langsung dengan adanya sistem penilaian kinerja tenaga ahli ini. Pendidikan dan latihan dalam penggunaan sistem penilaian tenaga ahli ini oleh staf IT baru akan lebih mudah karena sistem yang dibangun memiliki user interface yang tidak rumit dan efektif.

\subsubsection{Regulasi/Kebijakan/Strategi}

Regulasi/kebijakan ada di tangan manajemen PT. Inacon Luhur Pertiwi berkoordinasi dengan satker Dirjen P2KP Kementerian PU Karena untuk mengaplikasikan sistem ini kewenangan ada pada PT. Inacon Luhur Pertiwi. Saat ini sistem PKTA ini hanya sebagai acuan bagi proyek PNPM Mandiri Perkotaan.

\subsubsection{Aspek Penelitian Lanjut}

\subsubsection{Pengembangan Ruang Lingkup}

Penelitian tentang sistem PKTA ini bisa dikembangkan untuk proyek lain atau divisi lain pada bagian penilaian di PT. Inacon Luhur Pertiwi.
Metode lain bisa dipakai untuk perbandingan dari metode Adaptive Neuro Fuzzy Inference System (ANFIS) yang penulis pakai, karena masih banyak metode yang bisa dipakai untuk mengembangkan sistem ini, tentunya agar sistem lebih efektif dan efisien.

\subsubsection{Pengembangan Kriteria/Indikator}

Kriteria dan indikator yang bisa dikembangkan untuk sistem ini mungkin berkisar pemantauan secara berkala, atau bisa juga dengan sejauh mana perbandingan nilai tenaga ahli tersebut setiap periode apakah menurun atau meningkat.

\subsubsection{Pengembangan Unsur/Variabel}

Unsur atau variabel adalah ketetapan dari Dirjen P2KP Kementerian PU jadi jika ada pengembangan atau penambahan harus dikonsultasikan kepada Dirjen P2KP.

\subsection{Rencana Implementasi}

Pada tahap ini prototipe penilaian kinerja tenaga ahli selanjutnya akan diimplementasikan pada perusahaan dengan

perencanaan seperti digambarkan pada tabel berikut:

\begin{tabular}{|c|c|c|c|c|c|}
\hline \multirow[t]{2}{*}{ No } & \multirow[t]{2}{*}{ Rencana Aktivitas } & \multicolumn{4}{|c|}{$\begin{array}{c}\text { Lama } \\
\text { Pengerjaan } \\
\text { (Minggu) }\end{array}$} \\
\hline & & $\mathbf{I}$ & II & III & IV \\
\hline 1 & $\begin{array}{l}\text { Persiapan software dan hardware yang } \\
\text { akan dipakai }\end{array}$ & & & & \\
\hline 2 & $\begin{array}{l}\text { Pengumpulan informasi mengenai } \\
\text { gedung atau tempat sistem akan dipasang }\end{array}$ & & & & \\
\hline 3 & Analisis deskripsi umum sistem & & & & \\
\hline 4 & $\begin{array}{l}\text { Perancangan antarmuka program secara } \\
\text { lengkap }\end{array}$ & & & & \\
\hline 5 & Penulisan kode program & & & & \\
\hline 6 & Pengujian program & & & & \\
\hline 7 & $\begin{array}{l}\text { Implementasi dan Evaluasi program } \\
\text { aplikasi }\end{array}$ & & & & \\
\hline
\end{tabular}

\subsubsection{Pengembangan Metode/Teori Pisau Analisis}




\section{Kesimpulan dan Saran}

\subsection{Kesimpulan}

Setelah memaparkan keseluruhan dari penelitian dan dengan melakukan analisis sesuai dengan penulisan yang ada, maka dapat diambil kesimpulan sebagai berikut :

1. Hasil uji kelayakan perangkat lunak, cukup optimal karena nilai standar SQA $=80.08$ untuk suatu kualitas perangkat lunak yang baik. Sehingga prototipe pemodelan tersebut diharapkan bisa digunakan untuk memprediksi penilaian kinerja tenaga ahli.

2. Prototipe sistem penilaian kinerja tenaga ahli PNPM Mandiri Perkotaan dikembangkan dengan pendekatan logika Adaptive Neuro Fuzzy Inference Sistem (ANFIS)

3. Prototipe sistem penilaian kinerja tenaga ahli pada kegiatan pelaksanaan proyek dengan sistem pendukung keputusan dengan pendekatan logika Adaptive Neuro Fuzzy System (ANFIS) lebih cepat dan mendekati akurat daripada penentuan kinerja Tenaga Ahli secara manual.

4. Prototipe sistem penilaian kinerja tenaga ahli PNPM Mandiri Perkotaan dengan pendekatan logika Adaptive Neuro Fuzzy System (ANFIS) menggunakan 4 variabel dalam menentukan keputusan.

5. Empat variabel yang dijadikan variabel fuzzy mempunyai himpunan fuzzy: KURANG, CUKUP, dan BAIK.

6. Pemodelan pembelajaran yang paling optimal yang menghasilkan nilai RMSE terendah untuk peroses validasi model adalah pemodelan dengan Hybrid dengan Membership Functions "gbellmf" dengan RMSE bernilai 0.000063629 .

7. Sedangkan pemodelan yang paling optimal yang menghasilkan nilai RMSE terendah untuk proses validasi model adalah pemodelan dengan Hybrid dengan Membership Functions "gaussmf" dengan RMSE bernilai 19.9988.

\subsection{Saran}

Dari hasil penelitian yang telah dilakukan maka penulis menyarankan:

1. Indikator-indikator dalam menetukan kinerja tenaga ahli dapat dikembangkan untuk penyempurnaan sistem.

2. Hasil penelitian aspek sistem, kesiapan sistem yang dapat mendukung hasil keputusan penentuan kinerja tenaga ahli. Sistem yang digunakan harus mendukung untuk memberikan hasil yang terbaik.

3. Hasil penelitian aspek manajerial adalah perlu disosialisasikan kepada seluruh tenaga ahli dapat memberikan reward dan punishment sebagai tindakan dari hasil kinerja masing-masing.

4. Studi penelitian lanjutan dapat diterapkan pada perusahaan. Penelitian ini dapat dikembangkan lebih lanjut dengan penajaman dan penambahan indikator.

5. Rencana implementasi dapat direalisasikan dalam waktu 4 minggu apabila prototipe GUI penilaian kinerja tenaga ahli yang diajukan tidak mengalami perubahan terlalu banyak.

6. Semoga penelitian ini dapat bermanfaat dalam penentuan kinerja tenaga ahli, dibutuhkan masukan, saran, dan kritikan agar dapat memperbaiki, mengembangkan dan menyempurnakan penelitian ini ke tahap yang lebih baik.

\section{DAFTAR PUSTAKA}

Dick Grote, (2002) Dick Grote, The Performance Appraisal Question and Answer Book: A Survival Guide for Managers. http://www.slideshare.

net/ngbaodien/business-management-dickgrote-the-performance-apprais (diakses 6 juni 2015 pukul $15.00 \mathrm{wib})$

Changjun Zhu, L. (2009) Changjun Zhu, L, .PSO-base RBF neural Network Model for Teaching Quality Evaluation. International Conference on Control, Automation and System Engineering, 47. 2009 
Changjun Zhu, L. (2009) Changjun Zhu, L, Selatan, 2012. .PSO-base RBF neural Network Model for Teaching Quality Evaluation. International Conference on Control, Automation and System Engineering, 47. 2009

Kusumadewi (2004) Kusumadewi, Sri. Purnomo, Hari, Aplikasi Logika Fuzzy untuk pendukung keputusan: graha Ilmu, Yogyakarta, 2004.

Marimin, (2010) Marimin, Nurul, Aplikasi Pengambilan Keputusan Fuzzy Dalam Manajemen Rantai Pasok: IPB Press, Bogor, 2010

Peng Dong, F. D. (2009) Peng Dong, F. D, .Evaluation for Teaching Quality Based on Fuzzy Neural network. International Workshop on Eucation Technology and Computer Science, 112. 2009

Kusumadewi (2002) Kusumadewi, Sri, Analisis dan Desain Sistem Fuzzy Menggunakan Fuzzy Toolbox Matlab. Yogyakarta: Graha Ilmu, 2002.

Kusumadewi (2010) Kusumadewi, Sri. Purnomo, Hari., Aplikasi Logika Fuzzy untuk pendukung keputusan, Edisi 2: graha Ilmu, Yogyakarta, 2010.

Kusumadewi (2010) Kusumadewi, Sri. Hartati, S., Neuro - Fuzzy : Integrasi sistem fuzzy dan jaringan syaraf: graha Ilmu, Yogyakarta, 2010.

Prabowo, (2009) Prabowo, Rahmadya Penerapan soft computing dengan matlab: Rekayasa Sains, Bandung, 2009.

Alvino, (2012) Alvino, Penerapan Adaptive Neuro Fuzzy Inference System Untuk Evaluasi Nilai Ujian Nasional Calon Siswa Baru SMK : Studi Kasus SMK Negeri 2 Kota Tangerang 